\title{
First Year Conception of Students in the Concept of Atom and Periodec System Elements
}

\author{
Bertha Yonata ${ }^{1}$, Dian Novita ${ }^{2}$, Utiya Azizah ${ }^{3}$. Mitarlis ${ }^{4}$ \\ \{berthayonata@unesa.ac.id ${ }^{1}$ \} \\ Universitas Negeri Surabaya ${ }^{1,2,3}$
}

\begin{abstract}
The first-year undergraduate chemistry education study program students come from high schools in various regions in East Java. In this study, students' conceptions of the concept of atomic and periodic system elements were obtained with a three-tier test instrument. Students choose one of the 5 answer choices, choose one of the 5 reasons provided, and determine the level of confidence in answering the question. As many as 31 Chemistry education students filled 3 questions related to the concept of atomic concepts and the periodic system of elements. The data obtained shows that there are still students who experience misconceptions and ignorance of the concept of the atomic concept and the periodic system of elements.
\end{abstract}

Keywords: Atomic Concept, The Concept of Periodic System Elements, Three-tier test

\section{Introduction}

First-year students have gained preliminary knowledge about the basic concepts of chemistry when they are in middle school. Based on interviews with students of the 2018 chemistry education study program, first-year students also still have difficulty in attending basic chemistry lectures which most of their material has been obtained in chemistry subjects in secondary schools. As a student in the Chemistry Education undergraduate program, students should have a correct understanding of chemical concepts. As a pre-service teacher, students should have sufficient ability to become professional teachers [1].

Sim and Daniel's research shows that the low overall level of understanding of basic chemical concepts of the participants, and their average level of understanding of chemical representations, are cause for concern [2]. Related to the concept of atomic theory and the periodic system of elements it turns out that several studies have been carried out to see the understanding profile of students' concepts including Papageorgiou [3]. Papageorgiou try to categorize misconception into two groups: a. Misconceptions concerning the lack of a distinction between the characteristics of substances at the macro-level and those of their atoms at the micro-level (such as molecules and ions), and b. Misconceptions concern the differences at the micro-level, (such as the molecule, the ion and / or the cell) [3]. Papageorgiou's research also found data that the characteristics of the atom, linked to identity and behavior, revealed a significant number of students' misconceptions [3].

Atomic theory, concepts related to atoms and the periodic system of elements become the basis when students will study further material such as the concept of moles, chemical bonds, and chemical reactions. A strong understanding of the concepts related to atoms and the periodic system of elements is essential for students who are programming in chemistry education study 
programs. Likewise, if a student's misunderstanding (misconception) of concepts related to atomic and periodic systems will cause students to have difficulty understanding further chemical concepts. The most negative impact is that students will continue the misconceptions that they believe to be true. The opinions of teachers who try to explain the source of students' misconceptions, where the greatest source comes from the mental structure of students themselves, people's parents, electronic media, and peers.

In addition, the causes of misconceptions derived from three things, namely: (1) Naive ideas (derived from daily experience and language use of students); (2) Wrong concepts formed by students due to lack of understanding or misconception in the prerequisite concepts; and (3) Misconceptions transmitted from teachers through false or inaccurate teaching.

Based on this explanation, this study will discuss the profile of first-year students (class of 2019) in the Unisa chemistry education study program. The aim is to map the level of understanding of first-year students and become a benchmark in formulating appropriate lecture activities.

\section{Method}

The developed instrument is a three-tier test instrument. Each question consists of the first tier that presents 5 answer choices. The second tier contains 5 choices of reasons why students choose that option. The third tier presented 5 levels of confidence in the answers they chose. The interconnection of answers and the level of confidence are shown in Table 1.

Table 1. Proficiency Profile in chemistry.

\begin{tabular}{|c|c|c|c|}
\hline Tier 1 & Tier 2 & $\begin{array}{l}\text { Tier } \\
3\end{array}$ & Profile \\
\hline $\begin{array}{l}\text { Correct } \\
\text { (1) }\end{array}$ & Correct (1) & $\overrightarrow{2,5}$ & $\begin{array}{l}\text { Knowing the } \\
\text { concept }(\mathrm{K})\end{array}$ \\
\hline $\begin{array}{l}\text { Correct } \\
\text { (1) }\end{array}$ & $\begin{array}{l}\text { Correct } \\
\text { /wrong } \\
(1 / 0)\end{array}$ & $\begin{array}{l}< \\
2,5\end{array}$ & $\begin{array}{l}\text { Not knowing } \\
\text { the concept } \\
\text { (N) }\end{array}$ \\
\hline $\begin{array}{l}\text { Wrong } \\
(0)\end{array}$ & $\begin{array}{l}\text { Correct } \\
\text { /wrong } \\
(1 / 0)\end{array}$ & $\begin{array}{l}< \\
2,5\end{array}$ & $\begin{array}{l}\text { Not knowing } \\
\text { the concept } \\
\text { (N) }\end{array}$ \\
\hline $\begin{array}{l}\text { Wrong } \\
(0)\end{array}$ & $\begin{array}{l}\text { Correct } \\
\text { /wrong } \\
(1 / 0)\end{array}$ & $\begin{array}{l}> \\
2,5\end{array}$ & $\begin{array}{l}\text { Misconception } \\
\text { (M) }\end{array}$ \\
\hline $\begin{array}{l}\text { Correct } \\
\text { (1) }\end{array}$ & Salah (0) & $\begin{array}{l}> \\
2,5\end{array}$ & $\begin{array}{l}\text { Misconception } \\
\text { (M) }\end{array}$ \\
\hline
\end{tabular}

\section{Results and Discussion}

Data collection involved 31 first-year students. Students answer 3 questions on concepts related to atomic and periodic system elements. The first problem is related to the identification of the constituent particles of an atom or ion, the second problem is related to the location of an element in the element periodic table based on the electron configuration, and the third problem is the 
difference in the properties of an element in the element periodic table. Understanding of the Concepts Regarding Atom and the Periodic System of Elements of firs-year students illustrated in Table 2. Conception profile comparison in Figure 1.

Table 2. Profile of First-Year Students' Understanding of the Concepts Regarding Atom and the Periodic System of Elements.

\begin{tabular}{|c|c|c|c|c|c|c|c|c|c|c|c|c|}
\hline \multirow{2}{*}{ Student } & \multicolumn{4}{|c|}{ Question 1} & \multicolumn{4}{|c|}{ Question 2} & \multicolumn{4}{|c|}{ Question 3} \\
\hline & $\mathrm{T} 1$ & $\mathrm{~T} 2$ & $\mathrm{~T} 3$ & $\mathrm{P}$ & $\mathrm{T} 1$ & $\mathrm{~T} 2$ & $\mathrm{~T} 3$ & $\mathrm{P}$ & $\mathrm{T} 1$ & $\mathrm{~T} 2$ & $\mathrm{~T} 3$ & $\mathrm{P}$ \\
\hline S1 & 1 & 1 & 5 & $\mathrm{~K}$ & 0 & 1 & 5 & $\mathrm{M}$ & 0 & 0 & 5 & $\mathrm{M}$ \\
\hline $\mathrm{S} 2$ & 0 & 0 & 4 & M & 0 & 0 & 3 & M & 0 & 0 & 3 & M \\
\hline $\mathrm{S} 3$ & 1 & 0 & 4 & M & 1 & 0 & 5 & M & 0 & 0 & 4 & M \\
\hline S4 & 0 & 0 & 3 & M & 1 & 0 & 4 & M & 0 & 1 & 4 & M \\
\hline S5 & 1 & 1 & 5 & $\mathrm{~K}$ & 1 & 1 & 5 & $\mathrm{~K}$ & 0 & 0 & 3 & M \\
\hline S6 & 1 & 1 & 5 & $\mathrm{~K}$ & 1 & 0 & 5 & M & 1 & 1 & 5 & $\mathrm{~K}$ \\
\hline S7 & 1 & 1 & 5 & K & 1 & 1 & 5 & $\mathrm{~K}$ & 1 & 0 & 4 & M \\
\hline S8 & 0 & 1 & 5 & M & 0 & 0 & 5 & M & 0 & 0 & 5 & M \\
\hline S9 & 1 & 0 & 4 & $\mathrm{M}$ & 0 & 1 & 5 & $\mathrm{M}$ & 0 & 0 & 3 & M \\
\hline S10 & 1 & 1 & 5 & K & 0 & 0 & 5 & $\mathrm{M}$ & 0 & 1 & 3 & M \\
\hline S11 & 1 & 1 & 5 & $\mathrm{~K}$ & 1 & 1 & 5 & $\mathrm{~K}$ & 0 & 0 & 4 & M \\
\hline $\mathrm{S} 12$ & 1 & 1 & 5 & K & 1 & 0 & 4 & $\mathrm{M}$ & 0 & 0 & 3 & M \\
\hline S13 & 0 & 0 & 3 & M & 1 & 0 & 4 & M & 0 & 1 & 4 & M \\
\hline S14 & 1 & 1 & 5 & $\mathrm{~K}$ & 1 & 1 & 5 & $\mathrm{~K}$ & 0 & 1 & 3 & M \\
\hline S15 & 0 & 0 & 1 & $\mathrm{~N}$ & 1 & 1 & 5 & K & 0 & 0 & 1 & $\mathrm{~N}$ \\
\hline S16 & 1 & 1 & 5 & K & 1 & 1 & 5 & K & 1 & 1 & 3 & $\mathrm{~K}$ \\
\hline S17 & 1 & 1 & 5 & K & 1 & 1 & 5 & K & 1 & 1 & 2 & $\mathrm{~N}$ \\
\hline S18 & 1 & 1 & 5 & K & 1 & 1 & 5 & $\mathrm{~K}$ & 0 & 0 & 2 & $\mathrm{~N}$ \\
\hline S19 & 1 & 1 & 5 & K & 1 & 1 & 5 & K & 0 & 0 & 3 & $\mathrm{M}$ \\
\hline S20 & 1 & 1 & 4 & K & 1 & 1 & 4 & K & 0 & 0 & 2 & $\mathrm{~N}$ \\
\hline $\mathrm{S} 21$ & 0 & 1 & 5 & M & 1 & 1 & 5 & $\mathrm{~K}$ & 0 & 1 & 3 & M \\
\hline $\mathrm{S} 22$ & 1 & 0 & 5 & $\mathrm{M}$ & 1 & 1 & 3 & K & 0 & 0 & 2 & $\mathrm{~N}$ \\
\hline $\mathrm{S} 23$ & 0 & 0 & 1 & $\mathrm{~N}$ & 0 & 0 & 1 & $\mathrm{~N}$ & 0 & 0 & 1 & M \\
\hline $\mathrm{S} 24$ & 1 & 1 & 5 & K & 1 & 1 & 5 & $\mathrm{~K}$ & 1 & 1 & 3 & $\mathrm{~K}$ \\
\hline $\mathrm{S} 25$ & 1 & 1 & 5 & $\mathrm{~K}$ & 1 & 1 & 5 & $\mathrm{~K}$ & 0 & 1 & 4 & M \\
\hline S26 & 1 & 1 & 4 & $\mathrm{~K}$ & 1 & 1 & 4 & K & 0 & 0 & 4 & $\mathrm{M}$ \\
\hline S27 & 1 & 1 & 4 & $\mathrm{~K}$ & 1 & 1 & 4 & K & 1 & 0 & 4 & $\mathrm{M}$ \\
\hline S28 & 1 & 1 & 5 & K & 1 & 1 & 5 & $\mathrm{~K}$ & 0 & 0 & 3 & M \\
\hline S29 & 1 & 1 & 5 & K & 1 & 1 & 5 & K & 0 & 0 & 4 & $\mathrm{M}$ \\
\hline S30 & 1 & 1 & 5 & $\mathrm{~K}$ & 1 & 1 & 4 & $\mathrm{~K}$ & 0 & 0 & 2 & $\mathrm{~N}$ \\
\hline S31 & 1 & 1 & 5 & $\mathrm{~K}$ & 1 & 1 & 5 & $\mathrm{~K}$ & 1 & 1 & 4 & $\mathrm{~K}$ \\
\hline
\end{tabular}

T1: Tier 1; T2: Tier 2; T3: Tier 3

\section{Conception Profile Comparision}

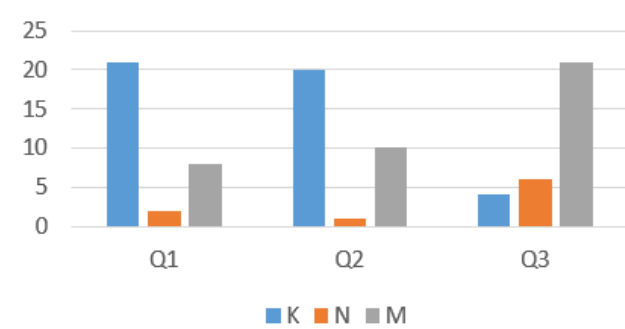

Fig. 1. Conception profile comparision.

Question 1: The number of protons, neutrons, and electrons in a species $\left(\_8^{\wedge} 17\right) \mathrm{O}$ in a row is ... 
In question 1 , only 8 out of 31 students misconceptions about the constituent particles. As many as 21 students have learned the concept of the constituent particles. This shows students' understanding that Atoms are the smallest particles of an element and building blocks of everything seen around us and atoms retain the characteristics of that element and are responsible for the combinations of elements found in molecules and compounds [4]. The choice of answers most chosen by students who experience misconceptions and do not know the concept is an error in counting the number of neutrons and electrons in the species. Students assume the number of neutrons is the same as the number of protons while the number of electrons is the mass number minus the atomic number.

Sarikaya's research shows that students held misconceptions on a variety of science concepts, modeling was quite useful in the teaching of science [5]. Students' misconceptions could be remedied through the use of models. To prevent or reduce misconceptions on types of questions such as question 1, in learning the teacher can use 2 or 3 -dimensional modeling to explain the calculation of the number of protons, neutrons, and electrons. If this misconception is not addressed it will lead to further misconceptions on the concept of ions because students cannot correctly calculate the number of electrons possessed by an elemental atom [6]. This is corroborated by Thompson's research which concluded that learning in science can be considered to be a sequential process, so can the development of misconceptions, so that once a misconception has been acquired it may be carried on and built upon further question 2: Which element with atomic number 37 includes which group and which block? In question 2 the number of students experiencing misconceptions is 10 , with the number of students who know the concept as many as 20 [6]. Only 1 student who does not know the concept of the location of an element in the SPU based on its electron configuration. For elements with atomic number 37 the correct electron configuration should be :

$$
37 \mathrm{Y}: 1 \mathrm{~s}^{2} 2 \mathrm{~s}^{2} 2 \mathrm{p}^{6} \quad 3 \mathrm{~s}^{2} 3 \mathrm{p}^{6} \quad 4 \mathrm{~s}^{2} \quad 3 \mathrm{~d}^{10} \quad 4 \mathrm{p}^{6} \quad 5 \mathrm{~s}^{1}
$$

With this configured, students should be able to determine the group and period elements, namely group IA period 5. But in reality, students who experience misconceptions and do not know the concept of choosing class VIII. They think that the group is obtained from the addition of electrons in the subshell $4 \mathrm{p}^{6}$ and $5 \mathrm{~s}^{1}$ that as many as 7 . Other students consider the electronic configuration to be ${ }_{37} \mathrm{Y}: 1 \mathrm{~s}^{2} 2 \mathrm{~s}^{2} 2 \mathrm{p}^{6} 3 \mathrm{~s}^{2} 3 \mathrm{p}^{6} 3 \mathrm{~d}^{10} 4 \mathrm{~s}^{2} 4 \mathrm{p}^{6}$ so this element is in group VIIA. If misconceptions occur as the result of category mistakes, then instruction needs to focus at the categorical level [7].

Weak understanding of students related to the determination of groups and periods in the periodic system of elements can be caused by the weak concept of electron valence. Question 3: Sequentially the acidity of the following oxides i) $\mathrm{Rb}_{2} \mathrm{O}$; ii) $\mathrm{BeO}$; iii) $\mathrm{As}_{2} \mathrm{O}_{5}$.

Based on the data in Table 2, it can be explained that the highest misconception occurs in the third question relating to differences like an element in the periodic system of elements, as many as 21 out of 31 students. The acidic nature of some oxides is asked in this question. A total of 24 students did not answer correctly related to the acid-base nature of $\mathrm{Rb}_{2} \mathrm{O}, \mathrm{BeO}, \mathrm{As}_{2} \mathrm{O}_{5}$. Most students who experience misconceptions and do not know the concept consider the acidic and basic properties of oxide based on the Bronsted Lowry acid-base theory. According to Bronsted Lowry, acids are species that release protons, whereas bases are species that receive protons.

This misconception can also affect when students learn about salt. Salt-related misconceptions are conducted by Secken [8]. In Secken's study, it was found that under such conditions, it is inevitable for students to have misconceptions about "salt", this because in their course books, salt is expressed to be formed by the Bronsted and Lowry acid-bases [8]. 
There are still students who experience misconceptions on the basic concept of chemistry can occur because the learning process only transfers information about science processes such as observing, inferring, and predicting, without relating it to the science content or applying it to solve the real issues or problems of the society that is why students understanding reflected learning as 'scientific truths' making little linkage to core concepts of chemistry, as a result, students learn chemistry but could not understand their ideas towards those accepted by the chemists and did not make better sense of the way in which their environment works [1]. Awan experiments showed that students' understanding of the basic concepts of chemistry were strongly influenced by their everyday life experiences and conflicts with scientific views [1].

Misconceptions that still exist in first-year students for the basic concepts of chemistry can also be overcome by the concept of change method. This is based on the thought of Treagust which states that instructional features are oriented towards constructivist conceptual change perspectives, although not frequent, do occur in both studies to different degrees in participating countries [9].

\section{Conclusion}

Based on the data and analysis explained in the results and discussion, it can be concluded that more than $25 \%$ of the 31 first-year students of the chemical education study program are still experiencing misconceptions regarding concepts related to the atom and periodic system of elements. This concept is one of the basic concepts that become the foundation when students learn the next concepts such as the concept of moles, chemical bonds, acid-base, and electrolyte solutions.

If misconceptions are allowed to go on, it can be ensured that subsequent chemical concepts will also be difficult for students to understand and may even become a sustainable misconception. The curriculum is the most important thing to prevent and reduce the occurrence of ongoing misconceptions. Although misconceptions can be significant roadblocks, they can also present opportunities to enhance learning because when a student is confronted with an inconsistency between what they think is true and what is correct, the discrepancy may generate surprise or confusion.

Acknowledgments. A thank you to the rector of Universitas Negeri Surabaya and dean of mathematics and natural sciences faculty for the opportunity obtained by the author in research funded by Dana Kebijakan FMIPA Unisa in 2019.

\section{References}

[1] Yonata, B., Wasis, W., Sulaiman, R., Sudibyo, E., \& Prastiwi, M. S.: Profile of the Academic Competency of Chemistry Education Students. Atlantis Highlights in Engineering (AHE), volume 1. International Conference on Science and Technology (ICST 2018). pp. 188-191 (2018)

[2] Sim, J. H., \& Daniel, E. G. S.: Representational competence in chemistry: A comparison between students with different levels of understanding of basic chemical concepts and chemical representations. Cogent Education, 1(1), 991180. (2014)

[3] Papageorgiou, G., Markos, A., \& Zarkadis, N.: Understanding the atom and relevant misconceptions: Students' profiles concerning three cognitive variables. Science Education International Vol. 27, Issue 4. pp. 464-488 (2016) 
[4] Awan, A. S., Khan, T. M., Mohsin, M. N., \& Doger, A. H.: Students' Misconceptions in Learning Basic Concept 'Composition of Matter' in Chemistry. International Journal of Applied Science and Technology Vol. 1, No. 4. pp. 161-167 (2011)

[5] Sarikaya, M.: Prospective teachers' misconceptions about the atomic structure in the context of electrification by friction and activity to remedy them. International Education Journal, 8(1), 40-63. ISSN 1443-1475. Shannon Research Press. (2007)

[6] Thompson, F., \& Logue, S.: An exploration of common student misconceptions in science. International Education Journal, 7(4), 553-559. ISSN 1443-1475. Shannon Research Press (2006)

[7] Chi, M. T.: Two kinds and four sub-types of misconceived knowledge, ways to change it, and the learning outcomes. In International handbook of research on conceptual change (pp. 61-82). Routledge. (2013)

[8] Seçken, N.: Identifying Student's Misconceptions about SALT. Procedia Social and Behavioral Sciences 2. pp. 234-245 (2010)

[9] Treagust, D. F., \& Duit, R.: Conceptual change: a discussion of theoretical, methodological and practical challenges for science education. Cultural Studies of Science Education, 3(2), 297-328 (2008) 